\title{
Unit of Kinematic Viscosity
}

National Cancer Institute

\section{Source}

National Cancer Institute. Unit of Kinematic Viscosity. NCI Thesaurus. Code C69091.

A unit for measurement of the resistive flow of a fluid under the influence of gravity that

is the ratio of the viscosity of a fluid to its density. 